\title{
GESTIÓN CURRICULAR POR COMPETENCIAS EN LA EDUCACIÓN MEDIA Y SUPERIOR
}

\author{
Marco Emilio Bautista Buitrago \\ Magíster en Educación \\ Universidad Santo Tomás-Colombia \\ marcoebautista@gmail.com
}

\section{RESUMEN}

La obra que a continuación se reseña, presenta seis capítulos. En primer lugar, aborda tensiones, demandas y mitos del diseño curricular y contempla la posibilidad de una educación renovada, que priorice el aprender mediante el uso adecuado de la pregunta y la respuesta. Desde este ámbito la mirada y acción crítica del estudiante y del docente harían repensar y ver otra escuela con otra forma de hacer educación, en el que la ética demanda responsabilidad por cuanto se forma en el aprecio de lo que se hace.

Los autores contemplan la formación humanista en la escuela, ámbito desde el cual exponen la esencia de su obra, enfrentar la gestión curricular, desde donde la formación humanista se haga operativa, por ello se preguntan: ¿Cómo lograr una ruptura paradigmática desde el quehacer para centrar el currículo en el sujeto quien se conoce y desarrolla competencias? Además, cuestionan epistemologías, e inducen a que se replantee la tarea docente al igual que la pregunta del conocimiento y la noción de ciencia.

Consideran válido reflexionar la relación entre conocimiento y apropiación de saberes y también cuestionan a la escuela por considerar que el conocimiento científico es el único válido mientras lo demás es cultura general, circunstancia que los motiva a formular un problema: ¿Cómo podemos atender a nuestro conocer si para hacerlo tenemos que echar mano del mismo acto de conocer? No hay duda, promueven una práctica flexible en vez de rígida. Los autores desde las ciencias humanas y so- ciales perciben que la verdad está totalmente ausente de los procesos educativos, porque se llega a ella a través de simples puntos de vista, cuando demanda reflexión crítica, proceso poco frecuente en las aulas.

En el capítulo segundo se habla de complejidad y humanismo, y abordan el enfoque socioformativo por competencias llevado a la implementación de un currículo centrado en el sujeto, se apoyan en el pensamiento de Édgar Morin, en la trilogía de Zubiria y siguen el conocimiento y concepción de sujeto que adelanta Bernard Lonergan, sobre la dificultad de asimilar el nuevo aprendizaje en medio de la división humana. De igual manera con Morin el no poder conocer haciendo retratos fieles del exterior y con Domínguez quien considera la imposibilidad de hacer análisis por separado.

Con la preocupación de poder acceder a un nuevo aprendizaje, los autores postulan principios que dinamicen el pensamiento complejo, entre ellos: el hologramático, (El todo en la parte y la parte en el todo) interés que contemplan al articular las etapas a todo un proceso. El de recursividad, (relación causa efecto y viceversa) para los autores los procesos se regulan a sí mismos con base en la información y el mismo contexto, y permiten agregar mecanismos de flexibilidad y pertinencia. El de auto-organización (organización, autonomía e interacción y contexto), para los autores el currículo por competencias es un proceso humano y una actividad cultural en continua auto-organización. El dialógico (dialéctica) lo antagónico busca su complemento. En el currículo por competencias los estudiantes configuran sus estudios 
según sus expectativas y problemas, pues priorizan creatividad e innovación. El principio de la reintroducción del conocedor en todo conocimiento (conciencia e intersubjetividad). Esta facilita que estudiante, docente e institución se puedan ver a sí mismos en el proceso. En efecto los autores infieren que "las organizaciones educativas no pueden ser sistemas simples por considerar que el verdadero agente es el incesante proceso de intersubjetividad" por ello recomiendan desarrollar procesos en perspectiva holística y heurística para facilitar experiencias.

Igualmente, abordan aspectos relacionados con operaciones, niveles y exigencias, siguen a Lonergan, al considerar que las operaciones pertenecen al sujeto que tiende consciente e intencionalmente por niveles a objetos. $1^{\circ}$ estaría el nivel empírico (nivel sensible), es básico porque ofrece "algo" a procesar para poder entender, reflexionar, decidir (insights) y generar práctica, además porque requiere percepción, comprensión y juicio para ser objetivo. Del nivel empírico se deriva como $2^{\circ}$ la deliberación (toma de decisiones) nivel superior en el que se resuelve el sentido de la existencia con responsabilidad y libertad, en el que el juicio finalmente debe ser pleno en la acción, en la valoración y finalmente sustentado con las respuestas de vida. Desde los anteriores argumentos los autores proponen el currículo de enfoque socioformativo por competencias centrado en la tarea de poder objetivar las operaciones conscientes y atenderlas, introspectivamente.

En el capítulo tres entran su estudio en la teoría curricular, allí consideran que los modelos pedagógicos se diferencian por los procesos formativos, razón por la cual varía el enfoque curricular; desde ellos traducen la cultura y plantean procesos didácticos. Exponen además aspectos de modelos curriculares. Del tradicional sostienen que funciona sobre un orden preestablecido, en el que el razonamiento no es posible, su base epistemológica es el idealismo platónico y se justifica en una relación vertical. Del tecnócrata resaltan su base, presente en la visión administrativa e industrial de la educación, cuyo fin es promover una antropología mecanicista y su fundamento está en el positivismo, por ende, programa al hombre para que experimente, produzca y controle, y se centra en el docente y la planeación. Del crítico, creen que se centra en el diseño de objetivos de transformación, por ello, prima el aprendizaje y no la enseñanza; además, se apoya en una educación problematizadora y siente la necesidad de no separar docencia de investigación. Se sustenta en la teoría crítica. El humanista lo contemplan como propuesta alternativa ya que su interés está en el abordar a la persona como realidad compleja y centro del proceso de construcción del conocimiento científico.

Por lo anterior, los autores aciertan en valorar el "constante estar haciendo" que conllevaría a determinar los fines que se persiguen en proyectos formativos. El ejercicio heurísticohermenéutico se constituye, por ende, en el fundamento que permite expresar descubrimientos e interpretaciones que eviten caer en cuestiones técnicas. De tal forma que el punto de partida es una noción de ciencia como práctica social y no como trabajo desarrollado por expertos. Sobre el modelo humanista implica ver al "experto" como un facilitador con visión holística por cuanto que para los autores a la luz de Lonergan (1988) el hombre es un punto de vista en movimiento.

Para los autores la fuerza del modelo no está sólo en comprender mundos significativos, sino en apropiarse de procesos de significación y valoración que constituyen mundos y valores culturales, lo que denomina Lonergan (1999) "acto de intelección". El currículo propuesto implica, por consiguiente, construir los desafíos sociales en programas y planes de estudio académicos; entrar en la lucha de la que habla Bordieau (1981) entre reproducir los esquemas sociales que permean la sociedad o la búsqueda de alternativas que intentan romper con esa resistencia cultural. En efecto un nuevo plan de estudios representaría una concreción 
de la relación educación-sociedad, y la resignificación de la experiencia dialógica. Desde el modelo humanista, la propuesta de enfoque socioformativo cobra importancia en la gestión curricular para la formación de competencias; ésta promueve la idea de currículo integrado y problémico, permitirá el diálogo entre CentrosDepartamentos-Facultades, cuyo fundamento es la interdisciplinariedad y transversalidad. Sobre este horizonte socioformativo, los valores y las actitudes se educan siempre en contextos de realidad, o como dice Kolvenbach (1990), los valores están anclados en la mente, el corazón y en nuestras acciones, es a lo que vale la pena dedicar la vida. Con este enfoque pretenden construir puentes y desafíos sociales a fin de romper con el aislamiento actual que presentan las asignaturas desde la identificación y formulación de problemas del contexto.

En el capítulo cuatro, los autores se interesan por reconstruir desde la noción heurística un concepto de currículo; parten de las comprensiones que tienen los docentes y que lo visibilizan al mejorar su trabajo, lo que para Stenhouse (1987) es responder a la separación entre teoría y práctica.

Entre los currículos mencionados está el oficial, que sigue guías curriculares y su propósito es evaluar a los estudiantes y supervisar a los profesores. El operativo se centra en enseñar y evaluar; los estudiantes generan acuerdos informales con los profesores. El oculto impacta más en los estudiantes; se relaciona con problemas de género, autoridad y conocimiento escolar, entre otros. El nulo pregunta: ¿Por qué se ignoran temas? y los incluye. El adicional valora las experiencias fuera de las materias, en ocasiones es más significativo.

Entre los referentes teóricos para recordar el fin del currículo: Stenhause (1991) quien expone que un currículo es una tentativa para comunicar los principios y rasgos esenciales de un propósito educativo, abierto a discusión crítica y trasladado a la práctica. Para Porlan, currícu- lo "es la relación entre teoría y práctica educativa. "Posner lo contempla como un programa secuencial de estudios, con estándares, ruta de estudio y experiencias planeadas. Kurt Lewin lo considera como "la mejor teoría en la mejor práctica, y, a su vez, la mejor práctica con buena teoría". Mientras para Flores Ochoa (2002) es el ser consecuentes, de forma que la calidad del currículo dependerá de la calidad de los profesores que lo ejecutan. De modo que el docente es el indicador del capital cultural de una institución. Para los autores el problema central del estudio del currículo es el hiato existente entre nuestras ideas y aspiraciones haciéndose operativas. Por ende, los autores ofertan una propuesta curricular incluyente, formativa y novedosa; convergen en que elcurrículo es finalmente "entender la dinámica de la vida en la escuela y desarrollarla procedimentalmente, contemplada sobre todo la noción de hombre.

Un aspecto importante para destacar son los criterios fundamentales que plantean, en relación a evaluar la atinada gestión del currículo de una institución de educación media o superior. Consideran: a) Un currículo no se puede copiar mecánicamente de una institución a otra. b) Una institución con profesores intercambiables, confluye en ser genérica y de escasa productividad académica; por ello sus docentes son remplazables por cualquier otro. c) La institución debe trascender el aula de clase al proponer y desarrollar problemas propios del contexto. De no ser así, la institución ha hecho la opción por enseñar lo que no investiga y enseñar sin contextualizar. d) Flexibilidad, relacionada con el rediseño de programas y planes de estudio en los que se articula el desarrollo del conocimiento con la acción, de ahí que para Gibbons, el currículo requiere un cambio organizativo que implica pasar del aprendizaje centrado en los imaginarios de las disciplinas a uno centrado en problemas.

Como quinto capítulo, abordan las competencias, los autores consideran indispensable un proceso progresivo de transformación do- 
cente a fin de reorientar a los sujetos. Citando a Conn expresan, "Un nuevo horizonte en el objeto, requiere de un nuevo horizonte en el sujeto personal, por ende, las competencias desde la complejidad implican un cambio en la manera en que el docente y la institución entienden su labor y se comprometen con ella, además que planear por competencias es muy distinto a planear por objetivos por cuanto este último culmina en un cambio en los significados y creencias. Para los autores, este tema está en el centro del debate, pues su origen y desarrollo se remite al ámbito de la empresa, cuyo enfoque es puramente técnico. Sin embargo, para los autores implementarlas en la educación no es un retroceso el trabajar por competencias, lo contemplan como una gran oportunidad para plantear cambios e innovar.

Para sustentar su interés los autores se apoyan en: Noam Chomsky quien propone el concepto de competencia lingüística como estructura mental implícita. Él parte de una racionalidad crítica-comunicativa y de una visión social del ser humano, esto implicaría formar personas con la capacidad de enfrentar de manera reflexiva, responsable y creativa, los desafíos sociales. Wittgenstein, destacará que el lenguaje en su carácter sistémico regido por reglas y Habermas ahondará en la importancia de la interactividad (actividad interna, que implica movilidad de saberes por el sujeto) lo que posibilitaría la visibilidad de las competencias. En efecto, la lingüística las estudia como estructuras internas, mientras que la psicología conductual, aplicada en las empresas, las aborda como desempeños especiales de los trabajadores, idea posteriormente transferida a las escuelas y universidades. Por otra parte, se apoyan también los autores en Sternberg y Perkins quienes insisten en la inteligencia práctica que conllevan las competencias, trasladando al hacer lo pensado por el sujeto y con Gardner identifican el peligro de considerar las competencias como únicas y estandarizadas desde la advertencia de las inteligencias múltiples. Frente a los an- teriores planteamientos, para los autores el trabajo curricular y docente experimentará una importante modificación crítica y enriquecimiento pedagógico que resulta indispensable revisar y valorar.

Por otra parte, los autores abordan el tema de la problematización como base del currículo por competencias con enfoque socioformativo. Consideran que a la base de esta temática está la pregunta de Kant: ¿Qué hago cuando conozco? Manifiestan que cada uno al resolver los problemas opera y se aproxima a una respuesta; por ello, con Lonergan consideran que alcanzar una respuesta demanda un acto de apropiación y auto-apropiación, ejercicio que requeriría de atender el conocimiento, entenderlo, juzgarlo y valorarlo. El currículo por competencias lo proponen como una alternativa para abordar las falencias de los modelos y enfoques pedagógicos tradicionales, al transitar de la lógica de los contenidos a la lógica de la acción, con el ánimo de brindar respuestas claras. Este nuevo modelo genera nuevas formas de mediar procesos, busca que se esté en condiciones de identificar, interpretar, argumentar y resolver problemas pertinentes del contexto. Apoyados en Tobón, Pimienta y García (2010) consideran que el modelo de competencias apoya el acercamiento y el entrelazamiento de las instituciones educativas con la sociedad y sus dinámicas de cambio.

El enfoque socio formativo desde el proceso sistémico-complejo, "afronta retos (problemas) actuales y futuros, caracterizados por la ínter y transdisciplinariedad, la multiplicidad de relaciones en contexto, a la vez, se declara enemigo del trabajo fragmentado. La formación con base en competencias implica por tanto aprender a analizar y resolver problemas contextuales investigando. De no desarrollar los anteriores aspectos, el proceso de las competencias podría enfocarse sólo hacia la productividad que demanda el mercado. Desde el enfoque socio-formativo los autores proponen algunos aspectos que se deben contemplar al describir 
y formular una competencia. 1. En el caso de la formulación de la competencia debe incluir: a) el análisis de problemas del contexto, b) criterios de desempeño, c) evidencias. Con base en estos componentes se realiza la mediación en el proceso de aprendizaje y de evaluación de las competencias de los estudiantes. 2. La competencia se describe a partir de: a) un desempeño, b) un objeto conceptual, c) una finalidad y d) una condición de referencia. 3. Los criterios y las evidencias son la base del proceso de evaluación formativa de las competencias (se refieren al saber ser, saber conocer y saber hacer. De las actividades, se abstraen los criterios y se asocian a evidencias y se les da una ponderación tomando como parámetro el $100 \%$ de la competencia. Importante reconocer que una característica esencial de la competencia es que se debe demostrar y evidenciar. Por otra parte, las competencias se determinan a partir del dominio de las áreas de desempeño (ocupación o profesión). Los autores desde este estudio convergen en dos clases de competencias: las genéricas que hacen referencia a las competencias que son comunes a una profesión y las específicas que son propias de cada profesión y dan identidad a la misma.

Por último o en el capítulo seis, abordan las fases de la planeación didáctica desde el enfoque socio-formativo. Es un trabajo que requiere análisis, reflexión y crítica del docente y de la institución. No basta la descripción de la competencia, sino su planeación didáctica que ayude a docentes y estudiantes en su aprendizaje y evaluación. En efecto: a) retoma los criterios y evidencias y con base en ello se identifica una situación problema del contexto pertinente a la competencia, b) se construyen las activida-

des de aprendizaje, c) se realiza el proceso metacognitivo y finalmente d) se elabora la matriz de evaluación y se planifican los recursos necesarios. Además se sugiere dentro de este horizonte de planeación seguir desde el modelo socio-formativo las cuatro fases metodológicas que son:

1) Definir la competencia de la asignatura en la que se establece el perfil de egreso: aquí el punto de partida y el referente de formación lo constituyen el conjunto de competencias genéricas y específicas que se pretende adquiera el estudiante en la institución, de acuerdo al contexto y análisis de los problemas. Importante considerar que el perfil de egreso orienta todo el plan de formación, las estrategias y didácticas y procesos de evaluación. Incluye: a) datos del programa y curso; b) la competencia a formar en congruencia con la competencia disciplinar y las genéricas; c) el proceso de construcción de la competencia, en la que el verbo de acción es importante.

2) Definir el diseño de la planeación didáctica que comprende : a) la competencia de la asignatura en la que se integran saberes que buscan dar respuesta a problemas del contexto; b) se indican los problemas de aprendizaje que se buscan resolver con la competencia construida; 
c) se contemplan actividades del docente y de los estudiantes dentro de un horario (dependiente e independiente). Importante comprender que los contenidos de las competencias no son estáticos sino dinámicos, estos cobran vida en la resolución de las actividades y problemas, allí se contemplan las teorías, los conceptos, entre otros, como la metacognición (proceso reflexivo ante desempeños concretos). 3) Definir la evaluación de competencias, contemplando criterios, evidencias y ponderación requeridas en orden a las fases y actividades organizadas. Y finalmente, 4) Construir matrices de evaluación de doble entrada (matriz que se puede leer en sentido vertical y horizontal, es decir, lo que domina de toda la competencia y dentro de cada criterio) el fin es evaluar el aprendizaje y ofrecer posibilidades de crecimiento personal definiendo niveles de dominio (nulo, inicial, básico, autónomo y estratégico) dentro de esta dinámica no importa el cuándo se adquieren los saberes sino el qué es lo que se adquiere.

\section{COMENTARIO}

La obra Gestión curricular por competencias en la educación media y superior centra su interés en considerar como sustancial la acción de la formación profesional a partir de una educación basada en el estudio de los contextos sociales, en los que identificar problemas y promover la solución de los mismos mediante análisis y prácticas concretas se constituye en una nueva posibilidad para la academia en desarrollar estudios y proyectos articulados, favoreciendo así la gestión de una formación menos parcial y más social e integral.
Por esta misma razón, una educación que promueva competencias humanas y sociales en contexto, es una educación que genera transformaciones por cuanto identifica y promueve saberes y formas de ser, menos técnicos y más prácticos, reflexivos y favorables al evaluar una institución o un proyecto de vida personal. En otras palabras, las competencias permiten priorizar metas y definir acciones socio-formativas, contrarrestando el peligro de ser académicos prolíficos, sin respuestas sociales y con ideas muy parcializadas tanto de la historia como de la vida en su devenir.

\section{CONCLUSIÓN}

En conclusión, la importancia de la dinámica por competencias es el poder favorecer con frecuencia la pregunta, mientras que la importancia del trabajo por objetivos recae en la respuesta, una acción igualmente necesaria. Se espera la articulación de las dos operaciones, en las que prima la reflexión y la toma de posición sobre el contexto de estudio para luego desembocar en una respuesta estudiada que opere, no como un conocimiento aprehendido sino como un conocimiento investigado y aplicado.

Los invito a que lean juiciosamente está importante texto y consideren llevar a la práctica, una práctica que seguramente les ayudará a resolver el dilema de si primero la respuesta o la pregunta.

Juan Antonio García Fraile, Martín López Calva, Nelly Milady López Rodríguez y Alberto Aguilar Álvarez. Gestión Curricular por Competencias en la Educación Media y Superior, México, Gafra Editores, 2012, pp.200. 